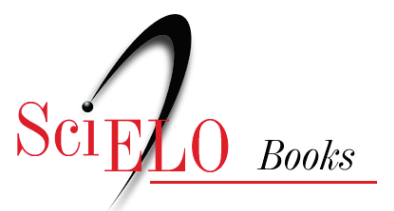

\title{
Prefácio
}

\author{
Paulo de Castro
}

CASTRO, P. Prefácio. In LISSOVSKY, A. 2000 anos depois: o renascimento de Israel [online]. Rio de Janeiro: Centro Edelstein de Pesquisas Sociais, 2009. pp. 5-17. ISBN: 978-85-7982-003-8.

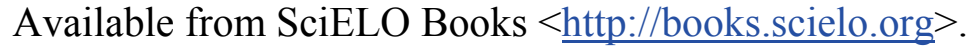

\section{(1) (1) (2)}

All the contents of this chapter, except where otherwise noted, is licensed under a Creative Commons Attribution-Non Commercial-ShareAlike 3.0 Unported.

Todo o conteúdo deste capítulo, exceto quando houver ressalva, é publicado sob a licença Creative Commons Atribuição Uso Não Comercial - Partilha nos Mesmos Termos 3.0 Não adaptada.

Todo el contenido de este capítulo, excepto donde se indique lo contrario, está bajo licencia de la licencia Creative Commons Reconocimento-NoComercial-CompartirIgual 3.0 Unported. 


\section{Prefácio}

Prefaciar um livro significa, a meu ver, associar-se a um empreendimento intelectual a que se reconhecem méritos, mas não implica a concordância automática e global com todas as suas teses.

Os problemas versados na pesquisa, a um tempo minuciosa e ampla, do professor Alexandre Lissovsky estão longe de ter sido definitivamente resolvidos pelos historiadores e, de certo modo, principalmente os acontecimentos que levaram ao nascimento do Estado de Israel, demasiado próximos para serem julgados com inteira objetividade. Contudo, dentro da perspectiva do autor é realizado um esforço considerável, para mostrar as raízes e o bem fundado das medidas e lutas, das razões e legitimidade da criação do Estado judeu.

O grande número de documentos que apresenta - muitos inéditos em português, o que só por si torna este trabalho de consulta obrigatória - e a longa transcrição de debates, por exemplo na Comissão Especial para a Palestina (UNSCOP), onde tem a probidade de apresentar opiniões de correntes políticas muito diferentes da sua, indicam uma intenção de abrir num sentido vasto o problema, embora cingindo-o ao propósito fundamental da linha cêntrica que é a justificação e defesa do Estado de Israel.

É dentro desta ótica que o livro deve ser lido e neste sentido, que pelo momento estou apenas determinando, constitui uma obra de interesse inegável, dispensando a consulta de muitos documentos e pondo à disposição dos interessados, de uma forma lógica e clara, argumentos básicos e importantes para se entender o nascimento do Estado de Israel. Em certo sentido, nestas páginas, o Estado nasce uma segunda vez, pelas suas mãos e pelo que os gregos chamariam de maiêutica.

O seu valor é não ser uma apologia cega mas submetida a um critério de demonstração que, embora subordinada a um objetivo inalterável, indica os caminhos do raciocínio. Ortodoxa quanto aos propósitos, é problemática quanto aos meios, o que equivale a dizer inteligente, mesmo quando 
algumas teses imponham, a meu ver, prudentes reservas, e algumas omissões exijam referência.

Defendo, e sempre defendi, o Estado de Israel contra todas as tentativas ou intenções de o destruir pelas armas, assim como estou certo de que haverá uma solução para o litígio judeu árabe, mas tendo como premissa a transformação socialista dos países árabes, não ditaduras bonapartistas representando apenas a revolução burguesa por meios militares, e visando a defesa de uma nova classe, internamente mais progressista em relação aos feudais, externamente mantendo categorias de comportamento oportunistas e procurando consolidar pelo ódio a Israel a coesão de forças e manter o domínio sobre as massas populares. O exemplo típico deste fenômeno é o nasserismo.

Não estou certo - e esta opinião é também a de Nahum Goldmann que a decisão de fundar o Estado de Israel, na data em que o fato se deu, tivesse sido a melhor decisão, nem que um Estado binacional a solução exata, tivesse sido impossível, mas como a História vivida não trabalha sobre hipóteses de trabalho, mas sobre realidades, e a criação do Estado judeu tem justificação - isso a distingue do simples fato consumado - é sobre essa realidade que temos de pensar ${ }^{1}$.

Não há portanto, da minha parte, uma discordância quanto à necessidade de preservar Israel de um ataque ou a urgência de se encontrar um entendimento, pois o considero indispensável.

Estou inteiramente de acordo quanto às responsabilidades terríveis do imperialismo britânico em não ter sido encontrada a verdadeira solução para o problema, bem como aos erros dos feudais árabes em não permitir, sempre apoiados por Londres, um acordo pela base entre a grande massa dos trabalhadores, árabes e judeus, na antiga Palestina.

Tudo isso já tratei em aulas, conferências e livros, e seria enfadonho repetir-me.

${ }^{1}$ A essência filosófica do trabalho do professor Alexandre Lissovsky, se não estou em erro, é precisamente distinguir uma realidade justificável de um fato consumado. Sempre dentro deste critério, sendo justificável, é, além de internacionalmente consagrado pela ONU, moralmente irreversível, enquanto um ato de força - sendo apenas isso - está submetido à lei da impugnação perpétua.
Creio apenas que o trabalho do professor Alexandre Lissovsky ficaria enriquecido se aceitasse, como fez Ben-Gurion, em 1949, que violências injustificáveis foram praticadas contra populações árabes e seus bens. "Nós ficaríamos profundamente indignados se nos tivessem dito há dois anos que os judeus seriam capazes de semelhantes atos"2.

E fica-nos devendo o professor Lissovsky um segundo volume, indispensável, em que trate dos problemas de Israel, entre os quais o dos refugiados. Este é fundamental, exigindo perfeita objetividade pois é entre todos se não o mais complexo pelo menos o mais delicado.

Não podem esses refugiados ficar à mercê das manobras de certos líderes árabes nem da indiferença, ou imobilismo, de outros líderes israelenses. Contribuir para a solução deste problema, dentro do racionalmente possível para Israel, e das obrigações inalienáveis dos países árabes e dos organismos internacionais, é ajudar ao entendimento judeuárabe.

Este entendimento, nas suas linhas globais e finais, implica, a meu ver, uma transformação fundamental nos países árabes, mas cumpre trabalhar por soluções parciais num processo que se tornaria irreversível. Em vez de se partir do entendimento judeu-árabe para a solução do problema dos refugiados, tudo indica que tenhamos de partir da solução do problema dos refugiados para o entendimento. As duas grandes potências que primeiro reconheceram o Estado de Israel, os Estados Unidos e a União Soviética, têm sobre este ponto obrigações de ordem moral irrecusáveis, assim como a ONU e todos os homens, pois todos nos devemos sentir humilhados com a existência subumana dessa massa de famintos e desesperados, sujeitos a todas as manobras políticas e a uma desolação apenas alimentada por quimeras. $O$ povo judeu que historicamente representou, inalteravelmente, um princípio de justiça tem de fazer em Israel e na Diáspora um esforço sobre-humano para resolver este problema. Sei que não o pode fazer unilateralmente nem pondo Israel em grave risco a

\footnotetext{
${ }^{2}$ André Falk, Israel terre deux fois promise. A descrição de Falk é longa e os fatos são graves. Ao citar Ben-Gurion, Falk procura evidentemente defender-se de uma acusação de parcialidade ou incompreensão. Devo dizer que aponta, também, uma série de documentos árabes, que tornam responsáveis, alguns dos seus líderes, pelo êxodo precipitado da população.
} 
sua segurança, mas é indispensável e urgente tentar, por seu lado, o que seja possível.

Quem teve a grandeza de criar um Estado, pode ter a heroica humildade de reparar um erro, e mesmo quando o erro tenha sido de todos, cabe ao governo de Israel demonstrar por atos, e de uma forma categórica, que está disposto a ir à raiz, retomando agora, já em fase de estabilidade e de consagração internacional, os momentos da sua criação. Os gregos julgavam que o destino é superior aos próprios deuses, mas a criação de Israel demonstra que a vontade do homem é superior ao destino. Que esta mesma vontade seja posta ao serviço da solução do problema dos refugiados, é o que desejam os seus amigos, que o sejam, como eu, menos por realizar o milagre da transformação do deserto em jardim - outros povos realizaram façanhas maiores sem por isso merecerem particular afeto - mas porque nasceu como encarnação de uma ideia e por confessada oposição a uma injustiça, e representa uma parcela do povo judeu. E ao dizer isto exprimo da forma mais elevada e mais discreta as razões essenciais da minha convicção de que o problema dos refugiados será resolvido ou tentará ser resolvido, por Israel. Ter por antepassado um Spinoza - e aqui poderia abrir-se um friso com dezenas de citações de humanistas incluindo Chaim Weizmann - tem os seus inconvenientes. O que de grande um povo ofereceu ao mundo - e por isso teve apoio na formação do Estado de Israel - não pode esgotar-se, exaurir-se, negar-se nos labirintos do poder.

Nasser é apenas um coronel do Oriente Médio que nada tem a ver com a cultura árabe de grande riqueza e finura como sabem todos os que se interessam pelo patrimônio humano, para além das fronteiras, das nações e das vicissitudes atuais.

Mas Eshkol, esse é um intelectual e sabe o que representa; atrás de si, glorificados, caluniados ou mesmo queimados, estão alguns dos símbolos da própria humanidade superior. Isto impõe obrigações de consciência, e até onde a segurança de Israel o permita, impõe iniciativas, imediatas e construtivas. Quando surgirem espero que os árabes do Oriente Médio pois a estes apenas me dirijo - não suponham que se trata de um ato de fraqueza. Porque é forte, o Estado de Israel pode ser generoso, e porque se trata de uma parcela do povo judeu deve saber a importância de não ver às suas portas legiões de refugiados. A responsabilidade é de muitos mas a consciência aflita está em Israel. Por isso a Israel nos dirigimos, certos de que a nossa obstinação é uma homenagem.

Eis o problema nodular que esperamos seja tratado pelo professor Alexandre Lissovsky, com seu pendor para a busca correta das fontes, e sua análise em muitos pontos sutil, num outro trabalho que nos fica devendo e mais ainda depois da repercussão justa do atual ensaio, que precisamente estabelece as premissas da grande problemática criada pelo Estado de Israel.

Tem todos os elementos para nos oferecer um estudo à altura deste que agora publica e a que anteponho algumas reflexões sobretudo como estímulo a que prossiga numa obra de inegáveis méritos em que me permito interpolar algumas notas e até sugestões de trabalho num espírito de fraterna colaboração.

Porque a contextura do livro é sólida, e o nervo vibrátil, e estes problemas dizem respeito à sorte de comunidades inteiras, é que não resisto à tentação de intervir um pouco além do que aconselha uma certa deontologia, ou norma, dos prefaciadores, que se limitam ao elogio da obra e do autor, pensando cumprir assim um dever de amizade, quando apenas incorrem num ato de estéril cortesia.

Elogiar o autor, neste caso, seria fácil e não demandaria mais que algumas linhas, mas colaborar com o autor numa crítica amplificante, isso impõe mais espaço e tempo. Sem economizar louvores ao trabalho do professor Alexandre Lissovsky, pois os merece, o mais importante é trabalhar um pouco em conjunto para clarificação dos problemas.

Pois não se trata de um livro episódico, mas dos que ficam como ponto inevitável de referência e de obrigatório estudo para todos os que se interessam pelo sionismo, suas origens e filosofia, pelo nascimento do Estado de Israel.

As referências neste ensaio, por tantos títulos valiosos, ao "affaire Dreyfus", dão, em meu entender, uma visão limitada, podem fazer crer, a um leitor menos informado, que o antissemitismo encarnado nesse episódio representou o pensamento do povo francês. 
A descrição das humilhações sofridas por Dreyfus é dada em todos os pormenores, enquanto a reação, que partiu dos intelectuais não judeus, como Emílio Zola e das próprias organizações operárias, fica sem uma necessária e justa invocação.

Não creio que para se defender o sionismo seja indispensável esquecer a grandiosa reação que se observou na França e afinal triunfou da minoria de antissemitas incrustados no Estado-Maior do exército, com apoio de algumas castas residuais que em Dreyfus combatiam, afinal de contas, a própria Revolução francesa por ter dado aos judeus, como disse Julien Benda, a "plena cidadania e dignidade".

Qualquer ideia de que as perseguições aos judeus, mesmo quando não explícita, nem mesmo subjacente, neste trabalho, mas podendo deduzirse por inferência subjetiva; qualquer sinal, mesmo longínquo, de que a perseguição aos judeus, nos países onde vivem, e aos quais pertencem, é inevitável, constitui um elemento nocivo para a necessária compreensão convivente no seio de qualquer nação.

Assim o "affaire Dreyfus", podendo ser apontado e devendo mesmo ser apontado para execração histórica dos seus responsáveis, impõe, ao mesmo tempo, o reconhecimento da grande luta empreendida contra os antissemitas que provocaram precisamente um dos maiores movimentos de opinião pública já desencadeado em qualquer época, e do qual participaram judeus e não judeus irmanados pelo mesmo espírito de justiça.

Se falamos no "affaire Dreyfus" devemos descrever não apenas a maneira como foi vilipendiado, mas a batalha que suscitou e o comportamento nobre da elite intelectual francesa e o apoio dado pelas organizações operárias, a sua massa e seus líderes, que terminou por uma vitória grandiosa que foi da própria democracia e dos ideais republicanos.

Não creio, por outro lado, que seja justa a alusão ao antissemitismo de Renan, fenômeno muito complexo e que diz respeito mais à preferência de que prevalecessem no cristianismo as influências gregas, por as julgar mais propícias a uma visão racionalista e tolerante do que as judaicas.
E naturalmente se apontamos intelectuais antissemitas, forçoso é incluirmos o judeu Gumplowicz ${ }^{3}$. Nem por isso se deduz que Gumplowicz seria partidário das câmaras de gás.

Sobre este problema do antissemitismo cumpre usar da maior prudência, para não assistirmos a espetáculos como o oferecido por David Rousset, que publicamente chamou antissemita a Steiner, o autor de Treblinka, porque apresentou certos fatos de uma maneira pouco exaltante para os judeus desse campo, quando não houve da parte desse autor, tão judeu, pelo menos, como Rousset, o intuito de denegrir, mas demonstrar a degradação a que pode chegar um grupo humano - de qualquer nacionalidade - quando, sem meios de defesa e numa engrenagem monstruosa, procura sobreviver.

E Hannah Arendt, escritora judia norte-americana, a autora do já famoso testemunho Eichmann in Jerusalem - A Report on the Banality of Evil, que foi ainda recentemente acusada de antissemitismo, por causa das suas teses sobre esse processo e em geral sobre o problema da culpabilidade? Por mim não aceito as suas teses, e considero-as mesmo perigosas, mas jamais poderia ocorrer-me a ideia de a considerar antissemita.

Quando um André Spire ${ }^{4}$ se viu obrigado a defender Romain Rolland da acusação de um irresponsável, que o considerava antissemita,

${ }^{3}$ Lukács em Sozialer Darwinismus, Rassentheorie und Faschismus demonstra que as teorias de L. Gumplowicz, com antecipação de meio século, contêm todas as bases racistas da aventura hitleriana. E Joseph Gabei, em La fausse conscience, diz: "Não deixa de ser humorístico notar que o autor de Der Rassenkampf, L. Gumplowicz, era judeu. Isso impediu os doutrinários do nazismo de o citar, mas nada retira ao título, pouco invejável, de ser um precursor do hitlerismo". E já que nos permitimos fazer uma advertência sobre certos aspectos deste problema complexo, lembremos que, ao contrário da crença de alguns sionistas, há quem defenda a existência do Estado de Israel sendo contudo antissemita. Este é o caso de Xavier Vallat em Souvenirs d'un homme de droite - prefácio de Charles Maurras.

${ }^{4}$ André Spire, Souvenirs a bâtons rompus. Também foi explorado o litígio, que terminou aliás por uma reconciliação, entre Romain Rolland e Léon Blum. Spire transcreve uma carta de Romain Rolland que é um documento histórico sobre as possibilidades de opção do povo judeu. Farei adiante uma referência a este documento.

A altitude e fraternidade do pensamento judeu revolucionário - para além de um sentido estrito de partidos - em relação aos não judeus, pode encontrar-se de uma forma exemplar em George Altman (ver o colóquio dos intelectuais judeus franceses de 1963 publicado sob o título La Conscience Juive - Prefácio de André Néher). 
verificamos como é duvidosamente certo transcrever uma passagem de um autor, e por algumas linhas situá-lo no friso dos inimigos do povo judeu.

Uma outra ideia a que julgo dever uma referência é a de centripetar o mundo no povo judeu, principalmente quando se trata de ofensas aos judeus que parece deixam indiferentes os que não têm o privilégio de o ser.

Ora isto se verifica na citação, quando das medidas contra os judeus na Palestina por parte dos ingleses, de Léon Blum, isolado do conjunto dos protestos do partido socialista, principalmente da ala esquerda de Marceau Pivert, o primeiro, e muito antes de Blum, que levantou seu protesto na França.

Talvez porque não sou judeu e tenho passado a vida inteira a protestar, junto com judeus e não judeus, tenho particular sensibilidade para estes fatos, e conheço bem a minha raça espiritual, a dos que não se curvaram ante o pretexto das ditaduras e as demonstrações do ódio racista, neste século, a partir do momento em que reconheci com espanto e horror as chagas que ainda marcam o viver do homem.

Numa carta a André Spire, datada de 1913, Romain Rolland, em resposta ao envio da obra Quelques juifs (trata-se no caso de Zangwill, James Darmesteter e Weininger), traçou o que no seu entender representam as opções do povo judeu. Segundo o autor de Jean-Christophe, compreendem três:

1 - "A generosa união do judeu com a pátria de adoção";

$2^{\circ}$ - "A grande ideia de que os judeus dispersos no mundo são e devem ser os representantes da Lei”;

$3^{\circ}$ - "O sonho de fundar um Estado judeu".

Para Romain Rolland são três posições legítimas, embora a primeira seja a melhor, a que mais promete em fecundidade para todos no domínio intelectual e moral.

Admitindo as três, adverte, contudo, que não podem as três aceitar-se ao mesmo tempo. Aí é que reside a opção, sem desdouro para as outras. "Il faut choisir", diz Romain Rolland, "et le choix ne saurait être le même pour tous les Juifs."
Este é um problema básico.

E um problema que não pode ser ignorado quando se trata de um livro sobre Israel. Num país que é uma democracia racial como o Brasil, as crianças de origem judaica que aqui nascem, brasileiros como todos os outros e com direitos iguais a todos os outros, não têm qualquer motivo para emigrar para Israel, mesmo podendo ter por Israel afetuoso interesse, o mesmo que possam dedicar a qualquer comunidade judaica. Não é necessário desinteressar-se de Israel, é apenas necessário que esse interesse não prevaleça sobre o que dedicam ao seu próprio país.

E, agora, voltemos ao livro do professor Alexandre Lissovsky.

A documentação que nos apresenta sobre a luta dos judeus por um Lar e a criação do Estado de Israel constitui um esforço de pesquisa único no Brasil.

Dentro da perspectiva do autor, a sua visão dos acontecimentos é ampla e não pode dizer-se que tenha exagerado aspectos negativos da orientação dos líderes árabes.

Pelo contrário, foi brando, talvez porque sendo judeu teve o nobre propósito de não ferir o outro povo que por força das circunstâncias é um tema central do livro. Mas eu que não sou judeu e me considero amigo dos árabes, do felá egípcio, cuja miséria conheci de perto, dos sírios apesar da sua turbulência, dos argelinos porque constituem hoje a maior esperança da África e do socialismo no terceiro mundo, posso dizer o quanto o professor Alexandre Lissovsky, sendo exato, usou, contudo, ao mesmo tempo, apenas da crítica o indispensável para a clarificação dos problemas.

Da personalidade do mufti de Jerusalém, diz o necessário para se conhecer a sua atuação funesta. Como historiador, cingiu-se, e muito bem, neste caso, aos acontecimentos da Palestina. Mas poderia apontar, se quisesse, e ninguém o poderia acusar de parcialidade, a ligação desse lúgubre personagem com os nazis.

Quando visitou Goebbels e Himmler, este teve a cortesia de lhe mostrar Auschwitz para o informar e o formar na nova técnica da exterminação em massa de judeus. 
Este mufti de Jerusalém era um dos líderes árabes e a maior desventura das massas árabes foi terem tido como líderes homens deste tipo.

Esta opinião que é minha, mas hoje, também, de muitos árabes, está discretamente apresentada ou subentendida nas páginas, sem dúvida valiosas, do professor Alexandre Lissovsky sobre a luta de judeus e árabes até a criação do Estado de Israel.

Toda a documentação sobre a Comissão Especial para a Palestina (UNSCOP), a que já fizemos referência, é, no sentido da informação histórica, um dos pontos altos do livro. E honra o autor a maneira ampla como apresenta os depoimentos, incluindo o dos comunistas Samuel Mikunis, secretário-geral do partido, Dr. Walter Ehrlich e Meir Vilner, sabendo-se perfeitamente que a orientação política do professor Alexandre Lissovsky é inteiramente diferente, para não dizermos contrária.

Mas num trabalho histórico todos os documentos devem ser consignados e o autor cumpriu fielmente esta norma mostrando a sua perfeita probidade. Importantes e menos conhecidos são os testemunhos de dois representantes da Liga Pró-Reconciliação e Cooperação Judeu-Árabe, Dr. Ernst Simon e Aharon Cohen.

O leitor encontrará, de uma forma mais ampla, no livro estes depoimentos, mas quero apenas transcrever as primeiras palavras do Dr. Ernst Simon: "O nosso objetivo é alcançar neste país uma união das duas nações. Acreditamos que um tal esforço poderá constituir a nossa maior contribuição ao bem-estar e unidade do mundo, especialmente por vivermos num dos seus lugares perigosos.

A Liga Pró-Reconciliação e Cooperação Judeu-Árabe não é um partido político. Compõe-se de várias organizações e personalidades da colônia judaica. Todos nós vemos na questão das relações judeu-árabes o ponto crucial da situação política neste país".

Este foi um grande movimento judeu de boa vontade, submerso como tantos outros pela política de intrigas da Inglaterra e seus aliados, das classes privilegiadas árabes e a imaturidade das massas da Palestina que não permitiu uma aliança, pela base, com sentido político e revolucionário, dos trabalhadores judeus e árabes. Ao conseguir impor a dialética do ódio e da interdestruição de duas comunidades, o Império Britânico é o responsável pelos problemas que até hoje existem, e constantes conflitos onde judeus e árabes ainda hoje pagam as consequências da política realizada durante o Mandato.

O episódio do Exodus nada fica a dever às atrocidades nazistas, e marca com um estigma uma certa política imperial em que a democracia e o respeito aos direitos do homem apenas existem nas Metrópoles.

A tragédia do Exodus mereceu algumas páginas de relevo ao professor Alexandre Lissovsky, como parte da grande tragédia do povo judeu na Palestina, em busca da salvação.

Creio firmemente que este trabalho, que tenho a honra de prefaciar, ajudará muitos a entender as raízes históricas de um combate e suscitará reflexões úteis. O mais importante não é a concordância, mas o debate sobre documentos e fatos apresentados pelo professor Alexandre Lissovsky.

Quero pela minha parte, antes de terminar, fazer um apelo aos meus amigos árabes do Oriente Médio, sobretudo aos que hoje estão muito próximos do poder na Síria, no sentido de um reexame de posições.

Esse reexame é indispensável e não devemos deixar nas mãos de Burguiba o que deve ser feito pela esquerda nos países árabes, mas com a certeza de que é urgente e será tentado, pelos elementos conservadores mais lúcidos, como o presidente da Tunísia, no caso dos mais lúcidos da esquerda hesitarem em fazê-lo.

Até hoje apenas um líder comunista árabe viu com clareza o problema das relações com Israel, o egípcio Fathi ar-Rãmla que no jornal $A l$ $M u$ árada (Oposição) preconizou a paz com Israel como meio de combate ao imperialismo, considerando um erro a política dos árabes contra o Estado judeu e a abertura de uma "segunda frente contra uma comunidade onde se podem entre os trabalhadores encontrar aliados na luta comum"5.

É inconcebível que um líder comunista da categoria de Khaled Baghdache não tenha compreendido a importância da formulação teórica de

${ }^{5}$ Uma referência a esta posição encontra-se no livro Communism and Nationalism in the Middle East de Walter Z. Laqueur. Algumas ideias de Fathi ar-Rãmla foram desenvolvidas pelo marxista A. R. Abdel Kader no seu livro Le conflit judéo-arabe. É um fio tênue, mas o único límpido que existe entre os marxistas árabes em relação ao problema de Israel. 
Fathi ar-Rãmla e mantenha sobre o conflito judeu-árabe ideias muito próximas do coronel Nasser ou dos coronéis que governam a Síria.

Mais grave ainda é a capitulação do partido comunista egípcio, ao considerar Nasser, na sua conferência de 24 de março de 1965, o "único líder da revolução egípcia". Que revolução? A isto leva o oportunismo segregado em Moscou, o qual faz do conflito judeu-árabe, tal como os Estados Unidos, um elemento da sua política. (Isto não exclui, contudo, a exigência perante a União Soviética e Estados Unidos de uma solução do problema no qual têm responsabilidades, mas sabendo que se trata de uma exigência tática, visando menos uma solução por Washington ou Moscou do que uma demonstração da total ausência de intenções por parte dos dois grandes de procurar a paz no Oriente Médio.)

Os marxistas árabes têm de reformular toda a sua posição em face de Israel, começando por aplicar com segurança e sem atenção aos interesses de nenhum modelo (seja o de Moscou ou Pequim) o método de interpretação histórica que proclamam científico, mas reduzem à categoria de uma ordem de serviço das casernas nasseristas.

Pode o comunista Samith Attyé, no governo da Síria, manter sem abandono do marxismo o princípio da guerra contra Israel?

Pode um Khaled Baghdache descer ao nível das piruetas islâmicosocialistas de um Michel Aflak, que por sinal considerava o sionismo e o comunismo como "inimigos mortais da Síria"?

Enquanto os marxistas árabes não fizerem uma revisão corajosa e doutrinalmente séria das suas posições em face do Estado de Israel serão inevitavelmente caudatários de generais ou coronéis, mais ou menos ao serviço de um grupo das classes privilegiadas, colorindo essa missão essencial com uma amizade à União Soviética - o que hoje por sinal está longe de representar qualquer índice de uma política interna progressista.

E sem essa revisão também não podem aspirar a uma política externa de frente anti-imperialista no Oriente Médio. Pois não há, como anteviu, num rasgo de genialidade, Fathi ar-Rãmla, uma política anti-imperialista no Oriente Médio sem um prévio entendimento com Israel.

No interesse geral e humano de dois povos, além de outras minorias do Oriente Médio, e ainda sob este ângulo específico da luta anti-imperialista, o entendimento judeu-árabe deve ser um ponto de honra assim como um ponto de coerência de todos os marxistas que não estão subordinados aos "aparelhos" deformantes e aviltantes de certos Estados que pela inércia mental e um abuso de terminologia são ainda considerados socialistas.

Paulo de Castro 